\title{
Exploring the environmental and economic potential for biogas production from swine manure wastewater by life cycle assessment
}

\section{Meng-Fen Shih}

FCU: Feng Chia University

Chyi-How Lay ( $\sim$ kfc0612@gmail.com )

FCU: Feng Chia University https://orcid.org/0000-0002-2114-7082

Chiu-Yue Lin

FCU: Feng Chia University

\section{Shen-Ho Chang}

FCU: Feng Chia University

\section{Research Article}

Keywords: Life cycle assessment, Cost-benefit analysis, Swine manure, Biogas, Environmental impacts, Electricity generation.

Posted Date: May 3rd, 2021

DOl: https://doi.org/10.21203/rs.3.rs-359637/v1

License: (9) This work is licensed under a Creative Commons Attribution 4.0 International License. Read Full License

Version of Record: A version of this preprint was published at Clean Technologies and Environmental Policy on July 18th, 2021. See the published version at https://doi.org/10.1007/s10098-021-02157-1. 


\section{Abstract}

Development of biofuels to replace fossil fuels by bioenergy systems has been attracting attention as an environmental-friendly process. Dealing with biowaste by anaerobic digestion not only disposes of wastes but also producing biogas during the treatment processes for providing the renewable energy source at low-cost while conserving fossil fuel. This study aims to use life cycle assessment and costbenefit analysis tools in evaluating and comparing the potential environmental impacts and cost benefits for the swine farm operation with and without a rapid-build anaerobic fermentor module installed into the original three-stage wastewater treatment system, which module helps biogas production as energy recovery in swine farms. The results indicate that the module could help reduce carbon footprint by $22.6 \%$, methane by $51.8 \%$, sulfur oxides by $92.6 \%$, nitrogen oxides by $74.2 \%$, carbon monoxide by $54.7 \%$, nitrous oxide by $28.6 \%$, suspended particulate by $95.4 \%$, and non-methane volatile organic compounds by $80 \%$. Using this module made the reductions of damage impacts were human health $82 \%$, ecosystem quality $59 \%$, and resource scarcity $87 \%$. The daily average biogas production was $46.38 \mathrm{~m}^{3}$ and its annual electricity generation income was 6,091 USD. This study allows identifying the lowest environmental impact to support the adoption of sustainable waste treatment and the opportunity for converting waste to be energy and utilization with economic benefits for small-scale swine farms.

\section{Introduction}

A livestock industry has huge and complex processes including the feeding of raw materials, product transportation, slaughtering and meat production, waste generation during breeding, and waste treatment. For the pollutant emission of livestock, about $44 \%$ is in the form of methane $\left(\mathrm{CH}_{4}\right)$ with the remaining part being almost equally shared between nitrous oxide $\left(\mathrm{N}_{2} \mathrm{O}\right) 29 \%$ and carbon dioxide $\left(\mathrm{CO}_{2}\right)$ $27 \%$. Issues of environmental impact caused by livestock industry have been discussed for a long time. In terms of activities, feed production/processing and enteric fermentation from livestock are the two main sources of pollutant emissions, respectively representing 45 and $39 \%$ of total emissions; manure storage and processing representing $10 \%$. Improper managements on livestock manure become a serious public concern due to its huge potential threat to public health and depletion of natural resources (Bui et al. 2011). With changes in living patterns and demand for diet in recent years, livestock industry has become one of the main agricultural industries in Taiwan (Tsai 2018). The livestock industry in Taiwan is under the jurisdiction of the Council of Agriculture ( $\mathrm{COA}$ ) of the Executive Yuan. The Animal Industry Act is drawn up for the purposes of regulating and providing guidance to the livestock farming business, preventing pollution, and facilitating the development of livestock industry (Taiwan COA 2010). Due to the limited usable land and high population density in Taiwan, the livestock industry and crop production are carried out on a small scale and concentrated in the central and southern regions of Taiwan. Furthermore, the swine husbandry output value accounts for half of the whole livestock production value in Taiwan has regarded as the most important agricultural economic project. Therefore, considering both economic development and environmental maintenance, the treatment of swine manure becomes even more important. In swine supply chains, the bulk of emissions relates to the feed supply and manure 
storage in processing, followed by energy consumption (FAO 2020). A three-stage wastewater treatment system including solid-liquid separation, anaerobic digestion and aerobic treatment is well used to treat the swine manure in Taiwan and its effluent can meet the discharge standard (Tsai 2009) even the industry still has to pay fees for water pollution control due to the authorization of the Water Pollution Control Act of Taiwan (Taiwan EPA 2018). Notably, the energy needs for running the system have no help for reducing energy consumption. In view of the change in livestock industry worldwide toward more concentrated animal feeding operations, environmentally-sound methods for the storage and disposal of manure are required (Cantrell et al. 2008). Meanwhile, the growing concerns regarding depleting fossil fuel reserves and adverse changes in climatic conditions due to ever-increasing greenhouse gas emissions made it essential to explore renewable energy sources (Godbout et al. 2008). The approach of producing bioenergy by biowaste that dealing with the waste problem, also bringing the benefits by producing energy at the same time.

There are many reports showing that bioenergy production from livestock manure is feasible and also has advantages both on environmental and economic concerns. Adeoti et al. (2014) estimated the biogas potential of livestock manure in Nigeria and its contribution to climate change mitigation. Roubík and Mazancová (2020) investigated the potential of dealing with animal waste by converting it into energy using small-scale biogas systems and evaluating its suitability at rural areas in northern Sumatra. Nasir et al. (2012) reviewed the potential of anaerobic digestion (AD) for biogas production from livestock manure wastes as well as compared the operating and performance data for various anaerobic process configurations. Ishikawa et al. (2006) had compared an on-farm biogas plant with a centralized biogas plant system from the energetics view-point. There are various researches studying livestock manure treatment technologies and management strategies (Alfa et al. 2020). Such as Abdelsalam et al. (2019) who used the life cycle assessment (LCA) to evaluate environmental impacts of manure treatment and compare $A D$ treatment with laser-radiation treatment for increasing biogas production from livestock manure. Biogas produced by AD consists mainly of methane and carbon dioxide and it can be utilized as a renewable energy in combined heat and power plants, as a vehicle fuel, or as a substitute for natural gas. Biomethane can also be utilized in industrial processes and as a raw material in the industry (Petersson and Wellinger 2009). Therefore, treating biowaste by AD is an appropriate way to dispose of wastes because its product, biogas, is a low-cost renewable energy which could conserve some fossil resources such as natural gas or coal.

The LCA has been an accepted international tool to transpose life cycle perspective principles into a quantitative framework for quantifying all relevant emissions, consumptions, depleted resources, and environmental impacts (ISO 14040-14044 2006). Regarding various biowaste treatment methods and their ability to produce bioenergy, a variety of LCA research has implemented. Börjesson and Berglund (2016) assessed the possible applications of biogas systems with attention to greenhouse gas (GHG) emissions and fossil fuel depletion. Bernsad and la Cour Jansen (2011) carried out an LCA research for comparing three different waste treatment systems and proved that biogas electricity had environmental benefits. Usack et al. (2018) used LCA results to identify the weak points for improvements. It has been also used to examine the environmental sustainability of biofuels to identify the key drivers of the 
environment profiles, also the benefits of possible new technologies for providing an evidence base for policymakers (Mabee and Saddler 2010). LCA is useful for environmental improvements (Hellweg et al. 2014; Renouf et al. 2017).

This study adopted a small-scale swine farm in central Taiwan as the research base. This swine farm had added a rapid-build equipment system, "Smart Green Electricity Production Module (SGEPM)", into the three-stage wastewater treatment system which is commonly used in Taiwanese swine farms. The SGEPM had an additional fermentation tank for producing more biogas than the three-stage wastewater treatment system. The biogas was introduced into a generator to generate electricity for being used at the swine farm. Compared with traditional digester structures of reinforced concrete (RC), SGEPM is easy to install at low cost and even can be built with recycled materials with no need to consider the cost of patents. It could be applied at small-scale swine farms. The objective of this study is to use LCA and costbenefit analysis (CBA) tools in evaluating and comparing the potential environmental impacts and cost benefits for the swine farm operation with and without using SGEPM. It aimed to (i) identify the lowest environmental impact to support the adoption of sustainable waste treatment and (ii) obtain the most appropriate model for small-scale-intensive livestock farms to reduce pollutants and emissions, decrease resource consumption, and produce renewable energy and reduce operating costs, so as to achieve the multiple sustainable goals of environment, economy, and energy. And (iii) this could be a suitable reference for some developing countries that lacking resources and funds, especially when the time or implementation ability does not allow to build large AD plants.

\section{Materials And Methods}

\subsection{Biogas production by swine manure wastewater}

\subsubsection{Swine manure feedstock}

The feedstock for the container-mobile anaerobic fermentor was collected from the swine farm in Taichung City, Taiwan. This swine farm raised about 900 heads, which was classified as a small-scale swine farm (less than 1,000 heads) and used food waste as the main feed. The wastewater $\left(3-5 \mathrm{~m}^{3} / \mathrm{d}\right.$, CMD) was mixed with swine manure and floor-washing. This swine farm used the three-stage treatment system to deal with the swine manure wastewater, which has a solid-liquid separator ( $0.5 \mathrm{~mm}$ mesh), an adjustment tank, five anaerobic tanks, two aeration tanks, and a sedimentation tank. The feedstock was the swine manure after solid-liquid separation in the adjustment tank. The characteristics of raw swine wastewater were chemical oxygen demand (COD) 33,190 \pm 4,660 mg/L, volatile solids (VS) 1,690 \pm 960 $\mathrm{mg} / \mathrm{L}$, total solids (TS) 2,540 $\pm 1,680 \mathrm{mg} / \mathrm{L}$, ammonia nitrogen $\left(\mathrm{NH}_{3}-\mathrm{N}\right) 1,310 \pm 690 \mathrm{mg} / \mathrm{L}$, and pH $6.17 \pm$ 0.7 .

\subsubsection{Design of Smart Green Electricity Production Module}

The rapid-build anaerobic fermentor set in the SGEPM had an anaerobic fermentation tank, that was on a forty-feet open container (W $2.4 \mathrm{~m} \cdot \mathrm{L} 12.3 \mathrm{~m} \cdot \mathrm{H} 2.5 \mathrm{~m}$ ); a large red polyvinyl chloride (PVC) bag (W $2.4 \mathrm{~m}$ 
- L12.3 m $\cdot \mathrm{H} 3.0 \mathrm{~m}$ ) was installed inside the container, accompanied with a $2.5 \mathrm{~m}^{3}$ stainless steel outflow trough (W $1 \mathrm{~m} \cdot \mathrm{L} 1 \mathrm{~m} \cdot \mathrm{H} 2.6 \mathrm{~m}$ ) (Fig. 1). The total capacity of the PVC bag was $80 \mathrm{~m}^{3}$, including liquid working volume $60 \mathrm{~m}^{3}$ and gaseous storage volume $15 \mathrm{~m}^{3}$. The feedstock flow rate was $3 \mathrm{CMD}$. A part of the produced biogas was pumped into a high-pressure gas storage tank. Fermentation temperature of $35^{\circ} \mathrm{C}$ was controlled using an electric water heater through external circulation. Biogas production was recorded using a flow meter. The biogas generator had a smart-control system. Following the concept of net-zero energy construction proposed by Deng et al. (2014), the produced biogas was recovered and combusted to generate electricity for operating the system in situ, which consumed no extra energy to run the module (Fig. 2).

\subsubsection{Operation strategy}

A co-feedstock strategy was applied for starting-up the acidogenesis fermentation using the swine manure. In the beginning, the anaerobic organisms of $15 \mathrm{~m}^{3}$ which was collected from a digester of the wastewater treatment plant, and the swine manure $15 \mathrm{~m}^{3}$ were pumped into the SGEPM as the seed inoculum and feedstock, respectively. Then swine manure was fed with $3 \mathrm{CMD}$ on the second day. After 10 days, the fermentor was switched to a continuous cultivation mode with a hydraulic retention time (HRT) of 20 days. Then, three periods of continuous cultivation (Continuous 1, Days 1-32; Continuous 2, Days 33-70; Continuous 3, Days 71-127) were carried out using the swine manure. The loading for these three periods was manure wastewater 3 CMD with COD of 15.5-37.9 $\mathrm{g} / \mathrm{L}$ depending on water utilization for cleaning the swine house. The swine manure wastewater (SMW) of 3 CMD with COD concentrations $26.21 \pm 4.67 \mathrm{~g} / \mathrm{L}$ was first fed into the fermentor during Days $1-32$ (Continuous 1 period). On Day 33, the solid swine manure (SSW) of $100 \mathrm{~kg} / \mathrm{d}$ and $3 \mathrm{CMD}$ was added to increase the organic loading. In order to enhance the biogas production by increasing the organic loading rate, the solid manure separated from the first stage of the original wastewater treatment process was collected to mix with the swine manure for the fermentor in the Continuous 2 period during days 33-70. However, after day 71 , the extra solid manure addition was stopped because the solid manure was applied (Table 1). 
Table 1

Biogas production during various periods of continuous cultivation.

\begin{tabular}{|c|c|c|c|}
\hline Operation period & $\begin{array}{l}\text { Continuous } 1 \\
\text { (Day 1-32) }\end{array}$ & $\begin{array}{l}\text { Continuous } 2 \\
\text { (Day 33-70) }\end{array}$ & $\begin{array}{l}\text { Continuous } 3 \\
\text { (Day 71-127) }\end{array}$ \\
\hline Organic loading & SMW $3 \mathrm{~m}^{3} / \mathrm{d}$ & $\begin{array}{l}\text { SMW } 3 \mathrm{~m}^{3} / \mathrm{d}+ \\
\text { SSW } 100 \mathrm{~kg} / \mathrm{d}\end{array}$ & $\operatorname{SMW} 3 \mathrm{~m}^{3} / \mathrm{d}$ \\
\hline \multicolumn{4}{|l|}{ Biogas production efficiency } \\
\hline Biogas production $\left(\mathrm{m}^{3} / \mathrm{d}\right)$ & $14.89 \pm 11.51$ & $32.46 \pm 10.99$ & $46.38 \pm 35.19$ \\
\hline Biogas production rate $\left(\mathrm{m}^{3} / \mathrm{m}^{3} / \mathrm{d}\right)$ & $0.25 \pm 0.19$ & $0.51 \pm 0.17$ & $0.57 \pm 0.33$ \\
\hline Methane production rate $\left(\mathrm{m}^{3} / \mathrm{m}^{3} / \mathrm{d}\right)$ & $0.18 \pm 0.13$ & $0.39 \pm 0.14$ & $0.39 \pm 0.24$ \\
\hline Methane production yield ( $\left.\mathrm{m}^{3} / \mathrm{kg} \mathrm{VS}\right)$ & $0.125 \pm 0.094$ & $0.273 \pm 0.098$ & $0.222 \pm 0.153$ \\
\hline $\mathrm{H}_{2}(\mathrm{ppm})$ & $15 \pm 9$ & $32 \pm 43$ & $15 \pm 14$ \\
\hline $\mathrm{H}_{2} \mathrm{~S}(\mathrm{ppm})$ & $2093 \pm 484$ & $2206 \pm 478$ & $2165 \pm 301$ \\
\hline $\mathrm{CH}_{4}(\%)$ & $71.7 \pm 2.8$ & $71.4 \pm 2.8$ & $70.8 \pm 2.7$ \\
\hline \multicolumn{4}{|l|}{ Wastewater treatment efficiency } \\
\hline Influent (g/L) & $26.21 \pm 4.67$ & $16.25 \pm 5.37$ & $25.22 \pm 8.12$ \\
\hline Effluent $(\mathrm{g} / \mathrm{L})$ & $7.32 \pm 0.99$ & $8.46 \pm 0.89$ & $9.54 \pm 2.96$ \\
\hline Removal efficiency (\%) & $71.5 \pm 5.5$ & $43.7 \pm 12.2$ & $50.9 \pm 12.1$ \\
\hline Influent & $6.94 \pm 0.40$ & $6.80 \pm 0.19$ & $6.21 \pm 0.51$ \\
\hline Effluent & $7.46 \pm 0.07$ & $7.47 \pm 0.13$ & $7.47 \pm 0.11$ \\
\hline$\Delta \mathrm{pH}$ & $0.52 \pm 0.42$ & $0.67 \pm 0.16$ & $1.26 \pm 0.48$ \\
\hline Influent (g/L) & $15.83 \pm 1.92$ & $7.37 \pm 1.27$ & $13.31 \pm 2.08$ \\
\hline Effluent $(\mathrm{g} / \mathrm{L})$ & $3.57 \pm 0.07$ & $4.46 \pm 0.86$ & $5.02 \pm 2.08$ \\
\hline Removal efficiency (\%) & $77.4 \pm 4.6$ & $41.0 \pm 10.9$ & $62.0 \pm 11.4$ \\
\hline
\end{tabular}

\subsubsection{Monitoring and analyses}

Gas volume was measured using a wet gas meter (Ritter, Gemmary) at temperature $\left(25^{\circ} \mathrm{C}\right)$ and pressure $(760 \mathrm{mmHg}$ ) (STP). The methane production efficiency including methane content, methane yield (the 
ability converting wastewater, based on feedstock kg VS, into methane, MY), and methane production rate (the rate of methane production in the reactor, MPR) were evaluated. The ethanol and volatile fatty acids (VFAs) concentrations were detected via a gas chromatograph equipped with a flame ionization detector, glass column $(1.6 \mathrm{~m} \cdot 3.2 \mathrm{~mm})$ which was packed with FON (Shinwa Chemical Industries Ltd) $10 \%$. The running temperature for oven, injection and detector were $175^{\circ} \mathrm{C}, 190{ }^{\circ} \mathrm{C} ; 200{ }^{\circ} \mathrm{C}$ respectively. The carrier gas was $\mathrm{N}_{2}$ with a flow rate of $60 \mathrm{~mL} / \mathrm{min}$. The gas composition was analyzed using a CHINA Chromatograph 8700T equipped with a thermal conductivity detector (oven $40{ }^{\circ} \mathrm{C}$; injection temperature at $40{ }^{\circ} \mathrm{C}$; detector $40{ }^{\circ} \mathrm{C}$; Argon as a carrier gas, packing, Porapak Q (Restek) as the packing material, mesh 80/100). The anthrone/sulfuric acid method was used to measure the hexose concentration.

\subsection{Life cycle assessment}

\subsubsection{Assessment goal, system boundary, and functional unit}

The evaluating procedure of LCA followed the guidelines of ISO 14040-14044 (2006) and Guinée et al. (2002). The assessment goal was to assess and compare the change of the target swine farm that replace the original wastewater treatment system (three-stage treatment and direct discharge) with installed the SGEPM for achieving the environmental and cost-benefit considerations. The system boundaries of this study were from the swine house operation to the wastewater treatment, it was the gate-to-gate assessment, included consumption of electricity and water for swine house basic operation, wastewater treatment system operation, and the energy recovery through biogas production for electricity generation to run the SGEPM. The utilization of the products obtained from the treatment processes was excluded. The system scopes and boundaries of this study for LCA are shown in Fig. 3. The primary data collected from the processes and flows of the swine farm were the year 2019. The inventory of the foreground and background data is summarized in Table 2. Based on the reasons of (i) the assessment scope includes swine fattening, swine manure, wastewater treatment, and the difference between before and after installed the SGEPM with the original wastewater treatment system that caused by the conversion of biogas into electricity for energy recovery. (ii) The assessment scopes involved the swine farm operation and considered the swine head number (farm-scale) relates to wastewater production, biogas production, and electricity conversion. "Useful module for small-scale swine farm" and "how this module is useful to the small-scale swine farm that can attract farmers involving with this design" were the main purposes to observe. The theme of environment and economy related to the swine farm operation issue were the points used by authors to stand for. The functional unit is defined as $1 \mathrm{~kg}$ live weight of swine at the farm gate. And a generally actual standard adult-live-swine weight had set at 250 $\mathrm{kg}$ in this study. 
Table 2

Main input and output data for the fulfillment of functional units by one head adult hog in the swine farm.

\begin{tabular}{|llll|}
\hline & Unit & $\begin{array}{l}\text { Swine farm with three-stage } \\
\text { treatment system }\end{array}$ & $\begin{array}{l}\text { Swine farm with SGEPM- } \\
\text { installed }\end{array}$ \\
\hline Input & & & 49.35 \\
\hline Electricity & $\mathrm{kWh}$ & 49.35 & 57.15 \\
\hline Heat & $\mathrm{MJ}$ & 57.15 & 39.51 \\
\hline Water & $\mathrm{m}^{3}$ & 39.51 & 8.13 \\
\hline $\begin{array}{l}\text { Manure } \\
\text { pumping/stirring }\end{array}$ & $\mathrm{kWh}$ & 8.13 & 3.01 \\
\hline $\begin{array}{l}\text { Electricity use in } \\
\text { SGEPM }\end{array}$ & $\mathrm{kWh}$ & - & \\
\hline Output & & & - \\
\hline CH ${ }_{4}$ emissions & $\mathrm{kg}$ & 4.57 & 0.56 \\
\hline Biogas & $\mathrm{m}^{3}$ & - & 1.16 \\
\hline Electricity & $\mathrm{kWh}$ & - & \\
\hline
\end{tabular}

\subsubsection{Impact assessment methods and outputs}

The Life Cycle Impact Assessment (LCIA) was conducted using ReCiPe2016 methodology (Huijbregts et al. 2017) characterization model incorporated with ecoinvent database v3.0 and referred to Weidema et al. (2013) and SimaPro v8.4 software (2017). The Endpoint characterization factors were directly related to the three areas of protection (human health, ecosystem quality and resource scarcity) that derived from Midpoint characterization factors per impact category used. The endpoints in ReCiPe2016 through different weighted-indicators and specific parameters, each protection area has its own unit in showing the definition of damage impacts. DALYs (disability-adjusted life years), relevant for human health, represent the years that are lost or that a person is disabled due to a disease or an accident. The unit for ecosystem quality is species $\times$ year, which means the local species loss integrated over time. The unit for resource scarcity is USD2013, which represents the extra costs involved for future mineral and fossil resource extraction (by US Dollars). Through the evaluation value of ReCiPe2016 after the weighting, directly shows the impacts on human health and the environment. The global warming potential is commonly referred to as carbon footprint and is used to assess the potential impact of different gaseous emissions on climate change (IPCC 2013). Taking into account the direct impact of the swine industry on gaseous pollutant emissions, the Greenhouse Gases Protocol was used for assessing the emission contributions of carbon footprint. In addition, effects of gaseous pollutants, such as sulfur oxides $\left(\mathrm{SO}_{\mathrm{X}}\right)$, 
nitrogen oxides $\left(\mathrm{NO}_{\mathrm{X}}\right)$, carbon monoxide (CO), and suspended particulate matter (PM) were using the Selected LCl indicators methods in SimaPro v.8.4, resulting from using scenarios of before and after installing SGEPM into the three-stage wastewater treatment system of the swine farm were all evaluated in this study.

\subsection{Cost benefit analysis}

Cost-benefit analysis (CBA) is one of the critical parameters in commercializing a technology. In this study, an economic analysis was applied for the full-scale anaerobic digestion process under the optimal condition. The main cost of an anaerobic digestion process includes capital investment $(\mathrm{Cl})$, operation and maintenance (O\&MC). Therefore, the internal rate of return (IRR), payback time (PBT) and sensitivity analysis were used as the decision-making tools for evaluating the economic feasibility (Choudhary et al. 2020). All the calculations for these indices were in USD. IRR is an important evaluation criterion and was calculated using the equation:

$$
\sum_{t=0}^{T} \frac{C_{t}}{(1+I R R)^{t}}-\sum_{t=0}^{T} \frac{C I}{(1+I R R)^{t}}=0
$$

The PBT was applied as another assessment criteria for decision-making and a diffident way to evaluate the period in which the expected cumulative cash flow would match the initial Cl. PBT was calculated by Equation 2 (Choudhary et al. 2020), where NCF was the expected net cash flow (USD). The PBT was defined as the discrepancy in earnings and operation and maintenance cost of the project every year:

$$
P B T=\frac{C I}{N C F}
$$

\section{Results}

\subsection{Biogas production in anaerobic mobile-container fermentor}

The biogas production performances including the content of biogas $\left(\mathrm{H}_{2}, \mathrm{H}_{2} \mathrm{~S}\right.$ and $\left.\mathrm{CH}_{4}\right)$, methane production rate and methane production yield at various continuous cultivation periods are shown in Figure 4 and Table 1. During days 1-32 (Continuous 1 period), the biogas production rate, methane production rate and methane production yield were $0.25 \pm 0.19 \mathrm{~m}^{3} / \mathrm{m}^{3}-\mathrm{d}, 0.18 \pm 0.13 \mathrm{~m}^{3} / \mathrm{m}^{3}-\mathrm{d}$ and $0.125 \pm 0.094 \mathrm{~m}^{3} / \mathrm{kg}$ VS, respectively with biogas having $\mathrm{H}_{2} 15 \pm 9 \mathrm{ppm}, \mathrm{H}_{2} \mathrm{~S} \mathrm{ppm} 2093 \pm 484 \mathrm{ppm}$ and $\mathrm{CH}_{4}$ $71.7 \pm 2.8 \% . \mathrm{H}_{2}$ was suddenly increased to $140 \mathrm{ppm}$ but methane was maintained at about $70 \%$ at Day 36 . The biogas production rate, methane production rate and methane production yield during Days 33-70 (Continuous 2 period) increased to $0.51 \pm 0.17 \mathrm{~m}^{3} / \mathrm{m}^{3}-\mathrm{d}, 0.39 \pm 0.14 \mathrm{~m}^{3} / \mathrm{m}^{3}-\mathrm{d}$ and $0.273 \pm 0.098 \mathrm{~m}^{3} / \mathrm{kg} \mathrm{VS}$, respectively with biogas content of $\mathrm{H}_{2} 32 \pm 43 \mathrm{ppm}, \mathrm{H}_{2} \mathrm{~S} 2,206 \pm 478 \mathrm{ppm}$ and $\mathrm{CH}_{4} 71.4 \pm 2.8 \%$. Due to a SSM shortage, the organic loading for the fermenter was switched back to SWW 3 CMD with COD $25.22 \pm 8.12 \mathrm{~g} / \mathrm{L}$. This COD concentration was much higher than the COD $16.25 \pm 5.37 \mathrm{~g} / \mathrm{L}$ in Continuous 2 
period which resulted from the rainy season causing low COD and SS concentrations. Therefore, the $\mathrm{H}_{2}$ content increased rapidly to $103 \mathrm{ppm}$ and HPR reached $1.25 \mathrm{~m}^{3} / \mathrm{m}^{3}-\mathrm{d}$ at Day 72 . However, the average BPR, MPR and MY in Continuous 3 period (Days 71-127) were $0.57 \pm 0.33 \mathrm{~m}^{3} / \mathrm{m}^{3}-\mathrm{d}, 0.39 \pm 0.24 \mathrm{~m}^{3} / \mathrm{m}^{3}-\mathrm{d}$ and $0.222 \pm 0.153 \mathrm{~m}^{3} / \mathrm{kg}$ VS, respectively, which closed to those values in Continuous 2 period. The COD and TS removal efficiencies reached $43.7-71.7 \%$ and $41.0-71.4 \%$, respectively during the continuous cultivation.

\subsection{Environmental impacts evaluated}

\subsubsection{Contribution of carbon footprint}

The total carbon footprint emissions for this swine farm were 28.19 and $21.83 \mathrm{~kg} \mathrm{CO}_{2}$-eq when based on using the three-stage treatment system and after installed the SGEPM, respectively (Table 3), and the contribution assessment of carbon footprint inventory for these two systems as shown in Fig. 5. The results had shown that the fossil-related factor was the main impact on the three-stage system $(25.89 \mathrm{~kg}$ $\mathrm{CO}_{2}$-eq). The same emission from the system with SGEPM was $5.24 \mathrm{~kg} \mathrm{CO}_{2}$-eq which was only one-fifth of the three-stage system. Notably, the system with SGEPM had a large contribution to the biogenic $\mathrm{CO}_{2}$ emission of $11.67 \mathrm{~kg} \mathrm{CO}_{2}$-eq which reached about eight times higher than that of the three-stage system. The $\mathrm{CO}_{2}$ emission by land transformation and the $\mathrm{CO}_{2}$ uptake was in the near values by two systems (Fig. 5).

Table 3

Carbon footprint assessment results of each operating item for the target swine farm before and after installing the SGEPM with the three-stage wastewater treatment system (unit: $\mathrm{kg} \mathrm{CO}_{2}-\mathrm{eq} / \mathrm{kg}$ ).

\begin{tabular}{|lll|}
\hline & $\begin{array}{l}\text { Swine farm with three-stage wastewater } \\
\text { treatment system }\end{array}$ & $\begin{array}{l}\text { Swine farm installed with } \\
\text { SGEPM system }\end{array}$ \\
\hline Swine feeding & 4.14 & 4.14 \\
\hline Farm operating & 21.08 & 13.70 \\
\hline Composting & 1.63 & 1.63 \\
$\begin{array}{l}\text { Wastewater } \\
\text { treatment }\end{array}$ & 1.34 & - \\
\hline SGEPM & - & 2.22 \\
\hline $\begin{array}{l}\text { Biogas } \\
\text { production }\end{array}$ & - & 0.10 \\
\hline $\begin{array}{l}\text { Smart-control } \\
\text { generator }\end{array}$ & - & 0.04 \\
\hline $\begin{array}{l}\text { Biogas recycling } \\
\text { system }\end{array}$ & 28.19 & 21.83 \\
\hline Total & & \\
\hline
\end{tabular}




\subsubsection{Contribution of gaseous pollutant emissions}

The results of the equivalence of pollution factors emissions were shown in Table 4 with total suspended particulate (TSP) and gaseous pollutants. The swine industry was always criticized for methane $\left(\mathrm{CH}_{4}\right)$ emissions and this indeed was seen from these results with emitting $10.26 \mathrm{~g}$ per kg live weight swine. Based on the general weight of an adult swine as $250 \mathrm{~kg}$, the average emission would reach $2.57 \mathrm{~kg}$ per $\mathrm{kg}$ live weight swine. In contrast, when the system installed SGEPM, the $\mathrm{CH}_{4}$ emissions were significantly reduced to $4.95 \mathrm{~g}$ per kg live weight swine, which value was only half of that of the three-stage system. The reduction of $\mathrm{CH}_{4}$ emissions was $1.33 \mathrm{~kg}$ per adult hog.

Table 4

Contributions of gaseous pollutant emissions by the swine farm before and after installing the SGEPM with the three-stage wastewater treatment system (unit: $\mathrm{mg} / \mathrm{kg}$ live weight swine).

\begin{tabular}{|llllllll|}
\hline Impact category & $\mathbf{S O}_{\mathbf{x}}$ & $\mathrm{NO}_{\mathbf{x}}$ & $\mathbf{N}_{\mathbf{2}} \mathrm{O}$ & $\mathbf{C O}$ & $\mathrm{TSP}$ & $\mathbf{C H}_{\mathbf{4}}$ & NMVOC \\
\hline Three-stage system & 8,221 & 5,109 & 478 & 3,382 & 7,496 & 10,258 & 705 \\
\hline Installed SGEPM & 603 & 1,319 & 341 & 1,532 & 344 & 4,950 & 141 \\
\hline
\end{tabular}

In addition, $\mathrm{SO}_{\mathrm{x}}$ and TSP were the other two categories with larger emissions discrepancies after installed the SGEPM, that the emission reductions were $92.65 \%$ for $\mathrm{SO}_{\mathrm{X}}$ and $95.41 \%$ for TSP. Moreover, the emissions of $\mathrm{NO}_{x}, \mathrm{CO}$ and $\mathrm{N}_{2} \mathrm{O}$ also reduced by $74.18,54.70$ and $28.56 \%$, respectively. On the other hand, although the emission of non-methane volatile organic compounds (NMVOC) was small, it was reduced by $80 \%$ after installed the SGEPM.

\subsubsection{Environmental impacts evaluated by ReCiPe2016 midpoint}

The evaluation results for the relative contribution of the swine farm using the three-stage wastewater treatment system and after installed the SGEPM had shown in Fig. 6. After installed the SGEPM into the three-stage wastewater treatment system, the section of ionizing radiation (IRP) got the highest reduction on the impact value, which was reduced from a former value of 3.20E-08 to $5.74 \mathrm{E}-10 \mathrm{DALY}$, which is only $2 \%$ of the former value. The next high reduction was water consumption potential (WCP) and fine particulate matter formation (PMFP). There were 3 sub-sections in WCP: human health, terrestrial and aquatic ecosystems. The values of WCP-human health, WCP-terrestrial ecosystem and WCP-aquatic ecosystem were reduced from 2.05E-06 to 8.64E-08 DALY, 1.25E-08 to 5.25E-10 species $\times$ year and $5.59 \mathrm{E}-$ 13 to $2.35 \mathrm{E}-14$ species $\times$ year, respectively. For the PMFP, it was reduced from 3.92E-05 to 1.68E-06 DALY. Noted that after installed the SGEPM into the original treatment system, the WCP and PMFP values were only $4 \%$ of those using the three-stage treatment system.

Fossil resource scarcity (FFP) and mineral resource scarcity (SOP) were the next two sections with high emission reductions after installed SGEPM into the treatment system with reduction values of $13 \%$ and 
$15 \%$, respectively. The global warming potential (GWP) effects on human health, terrestrial ecosystems, and freshwater ecosystems were reduced to $24 \%$; the photochemical oxidant formation effect on human health and ecosystem quality (HOFP, EOFP) was also reduced to $26 \%$. The impacts related to ecotoxicities, such as terrestrial ecotoxicity and freshwater and marine ecotoxicity (TETP, FETP, METP) were reduced to $28 \%$ and $36 \%$, respectively. The terrestrial acidification potential (TAP) was also reduced to $39 \%$. According to the assessed results on the midpoint, installed the SGEPM into the three-stage wastewater treatment system carried out huge benefits to environmental impacts.

\subsubsection{Damage impacts evaluated by ReCiPe2016 endpoint}

A comparison of before (original system) and after installing the SGEPM (SGEPM system) into the threestage wastewater treatment system in three damage impact sections had depicted in Fig. 7. All three damage impacts gave a significant reduction after installing the SGEPM. In terms of human health (HH), ecosystem quality (ED), and resource scarcity (RA), the reductions were $82 \%, 59 \%$, and $87 \%$, respectively. It is obvious that the SGEPM could improve the damage impacts caused by the three-stage treatment system in the swine farm and averagely reduced the damage impacts by $80 \%$. Table 5 summarizes the contribution assessment results of these two treatment systems in three damage impact sections.

Table 5

Contribution in three damage impact sections of swine farm operating by three-stage wastewater treatment system (original system) and after installed the SGEPM (SGEPM system). Assessed by ReCiPe2016 at the endpoint level.

\begin{tabular}{|llll|}
\hline Damage category & Unit & Original system & SGEPM system \\
\hline Human health & DALY & $7.70 \mathrm{E}-05$ & $1.39 \mathrm{E}-05$ \\
\hline Ecosystems & species×yr. & $1.94 \mathrm{E}-07$ & $7.90 \mathrm{E}-08$ \\
\hline Resources & USD2013 & 1.28 & 0.17 \\
\hline
\end{tabular}

\subsection{Economic evaluation}

In terms of cost-benefit analysis, this study started from the discrepancy in operating these two systems, and compared them with the concept of relevant information, and explained from the overall system planning. First, because the SGEPM system was directly grafted to the original wastewater treatment system, there was no increase in raw material and salary costs. Further, the cost of installing the SGEPM system was 70,000 USD, and the estimated durability was 25 years without a disability. Under the condition of value, the annual increase in depreciation costs was 2,800 USD. Next, the cost of utility electricity was calculated based on utility posted price, including the use of a substrate pump (1500 W) for 45 minutes per day and the use of a hybrid pump for 30 minutes per day (550 W), and the use of an intelligent control system for 12 hours per day $(250 \mathrm{~W})$ and the total electricity consumption was about 
0.1 USD/kWh (about 280 USD per year). In addition, the maintenance cost was calculated at $15 \%$ of the depreciation cost and it was 420 USD per year that made the annual increase in relevant costs was 3,500 USD. Therefore, the estimated annual benefit of installing the SGEPM system was 2,591.13 USD. Based on the useful life of 25 years, the cash expenditure of 70,000 USD invested in the SGEPM system at the beginning of the period, and the subsequent cash inflows were evaluated with the IRR being $6.55 \%$ and the expected recovery period being 12.94 years.

Next, based on the biogas production rate a calculation of the power generation revenue was done. Based on the posted price issued by CPC at $0.36 \mathrm{USD} / \mathrm{d}-\mathrm{m}^{3}$ (CPC Corporation 2020), the daily biogas production through the SGEPM system was $46.38 \mathrm{~m}^{3}$ and the daily gas production income was 16.69 USD. From these results, using the SGEPM system would increase the annual electricity generation income of 6,091.85 USD. This result was important in making a decision. Table 6 lists the cost-benefit estimate.

Table 6

The cost-benefit estimate list of the transformation of the three-stage wastewater treatment system to the SGEPM-installed (unit: USD/year).

\begin{tabular}{|ll|}
\hline Earning items & Revenue/cost \\
\hline Relevant revenue & $6,091.85$ \\
\hline Relevant cost: & \\
\hline Direct Material & 0 \\
\hline Wages Expense & 0 \\
\hline Depreciation Expense & $2,800.00$ \\
\hline Utility Expense & 280.13 \\
\hline Repair Expense & 420.00 \\
\hline Total relevant cost & $3,500.13$ \\
\hline Total relevant benefit & $2,591.72$ \\
\hline IRR & $6.55 \%$ \\
\hline Payback time & 12.94 year \\
\hline
\end{tabular}

\section{Discussion}

\subsection{Reduce the potential for carbon footprint emissions by installing the SGEMP}


The carbon footprint evaluation result shows that installing the SGEPM into the three-stage wastewater treatment system could reduce $22.56 \%$ emissions. Observing the total emission on SGEPM, which evaluation by each operating unit, that was higher $1.02 \mathrm{~kg} \mathrm{CO}_{2}-\mathrm{eq} / \mathrm{kg}$ than the original three-stage system. However, considering the whole swine farm operation included energy consumptions and energy recovery by electricity generation through biogas converting, the emissions were reduced by about $35 \%$ in the end. It gave a positive response for the reduction of carbon footprint while applying the SGEPM to produce biogas and recycling as electricity generation. In addition, due to the carbon fixation of biomass in the life cycle (Ducat and Silver 2012), for carbon footprint accounting purposes, biogenic carbon is considered as a $\mathrm{CO}_{2}$ reduction or a negative emission (ISO 2018). From this perspective, the carbon footprint emissions under the SGEPM system would be $-5.30 \mathrm{~kg} \mathrm{CO}_{2}$-eq indicating no carbon emissions. It proved that using bio-source waste converting to bioenergy have a greater opportunity to decrease carbon emissions.

\subsection{Mitigation for gaseous pollutant emissions}

Gaseous pollutants such as $\mathrm{SO}_{x}, \mathrm{TSP}$, and NMVOC were significantly reduced after using the SGEPM system and also in $\mathrm{NO}_{X}, \mathrm{CH}_{4}, \mathrm{CO}$, and $\mathrm{N}_{2} \mathrm{O}$ emissions. Grossi et al. (2018) had shown that these materials are the main gaseous pollutants emitted from livestock industry. Due to the installation of SGEPM, the pollutants that generally escaped into the air during the original wastewater treatment processes would be greatly reduced by the anaerobic fermentation process in SGEPM, including the contents of the treated wastewater that returned to the original system for discharging. This brought lots of benefits to the environmental impacts.

\subsection{Environmental assessment for damage impacts}

The damage impacts assessment considered the impacts on human health, environment and resource consumption with time-length factors, such as consideration by 20 or 100 years for the influence duration. Therefore, the comparison results of damage impact evaluation were more prominently presented the discrepancy of before and after installing the SGEPM than other evaluation results.

According to the feeding in swine farms, in order to maintain stable and good swine feeding efficiency and growth performance, high-protein formulas are often used in swine husbandry feeds. However, if it was not effectively used and decomposed, approximately 60-70\% of unused nitrogen in feeding would be excreted in manure again and caused pollution (Dourmed et al. 1999). Nitrogen-containing substances in manure include undigested dietary nitrogen such as protein, endogenous nitrogen, and microbial nitrogen. Undigested protein is rapidly converted by manure microorganisms into relatively unstable nitrogen-containing or sulfur-containing substances, such as ammonia, nitrate, nitric oxide, hydrogen sulfide, etc. The discharge of these substances into the environment would affect the surrounding environment. In addition, livestock industry in Taiwan is dominated by intensive farming in order to facilitate centralized management and shortening the raising time. Excessive heavy metals might be added to the feeds and the livestock wastewater might contain heavy metals and chemical residues. These materials could cause terrestrial pollution during recharging agricultural land. Therefore, livestock 
raising and fattening process, wastewater treatment and recycling are the keys to improve the industry and its environmental impacts. After installing the SGEPM into the three-stage wastewater treatment system, the reductions in $\mathrm{NO}_{x}, \mathrm{SO}_{\mathrm{x}}$ and relevant gaseous pollutant emissions were obvious. As IRP was relevant to metal residues of treated wastewater; HOFP and EOFP were relevant to the emission of $\mathrm{CO}$, $\mathrm{NO}_{X}, \mathrm{~N}_{2} \mathrm{O}, \mathrm{CH}_{4}$, and TSP. The reductions of TETP, FETP, METP, and TAP were relevant to the decrease of $\mathrm{NO}_{X}$ and $\mathrm{SO}_{x}$, which shown the interactive reaction in the midpoint and endpoint results by reductions in each impact category. All those results pointed to installing the SGEPM into the original three-stage wastewater treatment system had the environmental and economic benefits of (i) converting waste into energy while treating wastewater in swine farm and (ii) the energy-recovery supporting the SGEPM operation and swine farm's basic operation needs, that reduced the impacts of SOP and FFP. Among all the endpoint (damage impacts), resource scarcity (RA) had the largest impact reduction after installing the SGEPM, showing the SGEPM was greatly helpful in reducing resource consumption.

\subsection{Investment and operation/ Benefits and feasibility of SGEPM}

Under the active guidance of the government, most large-scale swine farms (with more than 2,000 heads) in Taiwan have installed a wastewater treatment system and biogas power generator (COA 2016). Even so, the actual benefit of biogas power generation is only a quarter of the estimated value by the government. This results from the customary raising model of using groundwater for flushing swine houses in Taiwan, which results in the dilution of swine manure wastewater and then lowering biogas production. In addition, the current methods and models used in commercializing biogas power generation and electricity sales are more suitable for large-scale swine farms. The costs of equipment and generators are too high for most of the small and medium-scale swine farms in Taiwan. Furthermore, swine farmers need to pay more time and manpower in negotiating and coordinating the specifications and installation procedures of different equipment with various manufacturers for installing and operating biogas power generation systems. Therefore, the SGEPM proposed in this study had easy-toinstall and easy-to-move equipment planning and design, which could be adopted to local conditions for small-scale swine farms. It could solve the problems of possible equipment and assembly requirements and meet the economic considerations that could be seen by cost-benefit evaluation. This system has more ability to achieve the closed cycle of material and energy flow in swine farms and is suitable for small and medium-scale intensive swine farms, to achieve the goals of enterprise self-reliance, resource recycling, economic improvement, reduction of environmental impacts, and energy sustainability.

In terms of economic analysis, the main object of this study was small to medium-scale swine farms, i.e., the swine farm with less than 2,000 heads swine. According to the swine farms within this range, if willing to plan facilities for biogas production in accordance follow by government regulations, the scale is firstly too large to the small-scale swine farms, and the secondary, the amount of wastewater produced by small-scale swine farms cannot meet the requirements for biogas production. That makes these swine farmers cannot to obtain government subsidies. And this makes the need to implement the equipment and manpower requirements are more difficult even impossible for these small-scale swine farmers. In addition, under the original wastewater treatment system, even if the quality of the treated wastewater 
can be discharged directly, the government still needs to charge considerable sewage treatment fees. Considered many factors, all the expenses were payout and no income. This context has been a long while, that is difficult for swine farmers to change it. Lastly, based on the small-scale swine farmers, considering the smaller scale and limited relative conditions of them, the IRR and PBT here are calculated based on the maximum potential cost and minimum average biogas production for controlling potential risks on investment. Generally speaking, the value of IRR and PBT will increase and decrease respectively with the scale-change of the assessed object, due to the cost allocation bases.

As far as concerned the current swine scale, can improve equipment operation efficiency, increase biogas production and reduce maintenance costs, which can increase IRR and reduce PBT from the original status of the swine farm operation. Another way is to increase the process-scale within the Relevant Range. A large increase in biogas production is also a way to increase IRR and reduce PBT. Critical capacity refers to the fact that under a certain range of capacity, some fixed costs will not increase, and as long as a certain capacity is crossed, fixed costs will increase accordingly, and this "maximum capacity under fixed costs without increasing" is Relevant scope. The "relevant range" means, under a certain range of production capacity, some fixed costs will not increase, and as long as a certain capacity is beyond, the fixed costs will increase accordingly. That is "the maximum capacity with no increase of fixed costs".

\subsection{Evaluating results and benefits comparison}

According to the study of Adeoti et al. (2014), it found the biogas potential from livestock manure represents a minimum of $1.62 \cdot 10^{9} \mathrm{~m}^{3}$ of biogas per annum in Nigeria. Among the survey results, the livestock manure composition includes cattle, swine, sheep, goats, and chickens. The swine average number was $6,369,286$ heads, and the biogas yield production was $0.38 \cdot 10^{6} \mathrm{~m}^{3} /$ day. The 2020 swine number survey (COA 2020) showed the total of 1,560,151 heads swine in small-scale swine farms in Taiwan. Based on the results in this study of installing the SGEPM into swine farms, it conservatively estimated the biogas production could reach $8.04 \cdot 10^{4} \mathrm{~m}^{3} /$ day, a minimum of $2.94 \cdot 10^{7} \mathrm{~m}^{3}$ per annum, and this is only the swine head number of small-scale swine farms, even excludes other livestock kinds. The comparison result shows that SGEPM has a higher benefit in biogas production by treating swine manure. The same research showed generating biogas from livestock manure for electricity and use in Nigeria is valuable. However, the majority of livestock reared under the extensive livestock farming and pastoral systems in Nigeria that made livestock manure collection to be the major challenge towards the plan realization. Livestock manure collection is enhanced by intensive livestock farming systems because where large quantities of livestock dung accumulate rapidly. This context also presents the advantages of applying SGEPM in Taiwan's intensive livestock industry, also reminds the considered point of the impact factors of feedstock sources for biogas production when the module applicated in other regions or countries.

The case-study of Putmai et al. (2020) had similar swine farm-scale and accustomed wastewater treatment systems to this study. Putmai et al. (2020) rearranged the cleaning and maintenance operation batches at month-intervals to propose two models for improving the conventional all-in/all-out batch 
management in Thailand medium-scale swine farm with 3,600 heads swine. The proposal was easy to implement and needless excessive equipment costs. However, it was insipid in promoting benefits and came without motivation: the biogas production from conventional management was $36,840-40,958 \mathrm{~m}^{3}$ per annum, and the increased rate by proposal models was 9 and $11 \%$ respectively. The improved production did not exceed $45,463.38 \mathrm{~m}^{3}$ production per annum. In addition, considering sold electricity at the price of $0.08 \mathrm{USD} / \mathrm{kWh}$, would income $193 \mathrm{USD} /$ year and save cost $295 \mathrm{USD} /$ year at the most. Calculated income of biogas production by SGEPM at the same price with $0.08 \mathrm{USD} / \mathrm{kWh}$, can reach 2,031 USD/year. The SGEPM has outstanding economic efficiency.

\subsection{Technological constraints and advantages for full-scale implementation}

The innovation of this study is the combination with practical application. First of all, the equipment for biogas production is easy to install and transport, and it can also be adjusted according to the actual base specification needs. The materials used can also be recycled materials, which has great advantages for both waste treatment and biogas production to obtain renewable energy. Moreover, because there is no patent fee, the cost threshold is much lowered, and the actual demand is more accessible and implemented. It is attractive to many small and medium-scale swine farmers who hardly apply for government subsidies because the scale range of swine farms couldn't meet the policy requirements. After all, compared with the cost/benefits and environmental impacts, the actual expenditure and income are more perceptible and resonated with swine farmers.

The AD processing process is the key for the entire SGEPM. The AD process takes four key stages names hydrolysis, acidogenesis, acetogenesis, and methanogenesis. The breakdown of feedstock in the absence of oxygen is facilitated by a combination of microorganisms present in each stage of the digestion process, which leads to the formation of digestate (decomposed feedstock) and a mixture of gases that includes $\mathrm{CH}_{4}$ gas as the main component (Al Seadi et al. 2008). The reviews by Goswami et al. (2016) mentioned the $A D$ process as a whole could be controlled by regulating the microbial consortia involved in it. The feedstock, $\mathrm{pH}$, temperature, and other physical parameters would be beneficial by optimization for microbial growth and viability and thus helpful for biogas production in the AD process. However, related to the microbiological and technical process of biogas production, which leads to the production process is complex and involves many different types of microorganisms. This leads to various research discusses the different aspects to be taken into consideration to achieve optimal degradation and gas production, and needs for the particular focus on operation management and microbiology (Schnürer 2016). Therefore, in order to make SGEPM more efficient and take into account long-term development, all of those affectable factors would be the main point for future research.

\subsection{Practical applications and challenges}

Anaerobic digestion (AD) is a unique process where different microbial species decompose organic materials in the absence of oxygen and has been widely practiced in full-scale facilities all over the world. However, the complexity of the challenges poses constraints to the understanding of the factors associated with the scale-up of the AD operations. 
According to upscale bioreactors is relatively easy due to the possibility to run them parallel in high quantities without modifying the individual reactors. And the condition must be the reactor runs at a desired steady-state, then its operating settings can be copied to other reactors such that the same steady state is reached in these reactors. As Garfi et al. (2016) say, basic design goals for a digester are a maximum volume production of biogas, also to allow for a continuous, high, and sustainable organic loading rate, as well as taking into account to minimize reactor volume. Achinas and Euverink (2016) suggest the digester design preferably considers the construction practicalities of both mixing and heat loss because the digester size has to be based on the available amounts of organic wastes. Depends on construction consideration, square and rectangular underground digesters are easier to build. However, a buildup of refractory compounds will reduce the effective operating volume of the digester over time because the flow will be stagnant in right-angled corners that make the mixing will be suboptimal, even might lead to process failure leading to extra downtime and maintenance. Besides, consideration of heat loss, the digester shape, material, location, and operating mode could influence the final decisions. In addition, according to Dussadee et al. (2017) research, digesters can operate in either a one-stage or multiple-stage digestion, which depends on the scale of operation and feeding characteristics.

The SGEPM proposed in this study is easy for installing and transportation and the highly rapid-mobilebuild of it is more feasible for implementation in any area with limited utilizable land and high-density population. Moreover, for increasing the biogas production by necessary needs, the anaerobic fermentor can be directly expended by increasing the number of containers and PVC bags. Most of the container sizes are formatted specifications, and each region and country having its own standard specifications. The biogas output calculation can be done based on the specifications of the region and the smartcontrol system settings can be adjusted for controlling the generator. It is an application advantage both of time and cost-benefits. This practice particularly appropriate for small and medium-scale swine farms which supply most sources for livestock husbandry in Taiwan. The module helps to bring considerable environmental and economic benefits to dealing with waste for conversion into energy. This is consistent with the current policy of actively promoting the application of biomass energy and promoting the concept of waste to energy with the Taiwan government. The module can help to connect to unwind the dilemma of lacking subsidy for small and medium-scale swine farms because the farm-scale and biogas production range couldn't meet the subsidy standard by the government. And proactive participation of private citizens that also can help to accelerate the implementation of policy goals.

\section{Conclusions}

The environmental and economic performance of installing the SGEPM into the three-stage wastewater treatment system had been analyzed with the detailed assessments conducting on environmental impacts and cost-benefit analysis. The SGEPM system was shown as the great appropriate module for small-scale-intensive livestock farms and it could efficiently reduce carbon footprint and relevant gaseous pollutants. Installing the module also could reduce damage impacts on human health, ecosystem quality, and resource scarcity and bringing economic benefits by daily producing biogas for energy recovery and increasing an annual electricity generation income of 6,092 USD. 


\section{Declarations}

\section{Acknowledgements}

The authors deeply appreciate the financial supports from the Ministry of Science and Technology, Taiwan (MOST 108-2221-E-035-036-MY3 and MOST 109-2221-E-035-028). An appreciation of the swine manure, sewage feedstocks, and energy data in the swine husbandry provided by the pig farms in Dali, Taichung, Taiwan was also acknowledged. There is no conflict of interest to claim in this study.

\section{References}

Abdelsalam E, Hijazi O, Samer M, Yacoub IH, Ali AS, Ahmed RH, Bernhardt H (2019) Life cycle assessment of the use of laser radiation in biogas production from anaerobic digestion of manure. Renewable Energy 142: 130-136 https://doi.org/10.1016/j.renene.2019.04.090

Achinas S, Euverink GJW (2016) Consolidated briefing of biochemical ethanol production from lignocellulosic biomass. Electron J Biotechnol 23:44-53

Adeoti O, Ayelegun TA, Osho SO (2014) Nigeria biogas potential from livestock manure and its estimated climate value. Renewable and Sustainable Energy Reviews 37: 243-248 http://dx.doi.org/10.1016/j.rser.2014.05.005

Alfa MI, Owamah HI, Onokwai AO, Onokwai AO, Gopikumar S, Oyebisi SO, Kumar SS, Bajar S, Samuel OD, llabor SC (2020) Evaluation of biogas yield and kinetics from the anaerobic co-digestion of cow dung and horse dung: a strategy for sustainable management of livestock manure. Energy, Ecology and Environment https://doi.org/10.1007/s40974-020-00203-0

Al Seadi T, Rutz D, Prassl H, Köttner M, Finsterwalder T, Volk S (2008) More about anaerobic digestion (AD). In Biogas Handbook. Al Seadi T, Ed. University of Southern Denmark: Esbjerg, Denmark pp 16-28

Bernstad A, la Cour Jansen J (2011) A life cycle approach to the management of household food wasteA Swedish full-scale case study. Waste Management 31: 1879-1896 https://doi.org/10.1016/j.wasman.2011.02.026

Börjesson P, Berglund M (2006) Environmental systems analysis of biogas systems-Part I: Fuel-cycle emissions. Biomass and Bioenergy 30: 469-485 https://doi.org/10.1016/j.biombioe.2005.11.014

Bui XT, Wolff A, Madsen M, Bang DD (2011) Fate and survival of campylobacter coli in swine manure at various temperatures. Frontiers in Microbiology 2: 262 https://doi.org/10.3389/fmicb.2011.00262

Council of Agriculture (Taiwan COA) (2010) Animal Industry Act. Executive Yuan, Taiwan, ROC

Council of Agriculture (Taiwan COA) (2016) Pig farms biogas power generation development plan. Executive Yuan, Taiwan, ROC 
Council of Agriculture (Taiwan COA) (2020) Report on the Number of Pigs Survey. Executive Yuan, Taiwan, ROC

Cantrell KB, Ducey TF, Ro KS, Hunt PG (2008) Livestock waste-to-bioenergy generation opportunities. Bioresource Technology, 99: 7941-7953 https://doi.org/10.1016/j.biortech.2008.02.061

Choudhary A, Kumar A, Kumar S (2020) Techno-economic analysis, kinetics, global warming potential comparison and optimization of a pilot-scale unheated semi-continuous anaerobic reactor in a hilly area: For north Indian hilly states. Renewable Energy 155: 1181-1190 https://doi.org/10.1016/j.renene.2020.04.034

Chinese Petroleum Corporation (CPC Corporation) (2020) Historical natural gas price. Taiwan, ROC https://vipmember.tmtd.cpc.com.tw/mbwebs/ShowHistoryPrice_8.aspx

Deng S, Wang RZ, Dai YJ (2014) How to evaluate performance of net zero energy building - A literature research. Energy 71: 1-16 https://doi.org/10.1016/j.energy.2014.05.007

Dourmad JY, Sève B, Latimier P, Boisen S, Fernandez J, Van der Peet-Schwering C, Jongbloed AW (1999) Nitrogen consumption, utilisation and losses in pig production in France, the Netherlands and Denmark. Livestock Production Science 58: 261-264 https://doi.org/10.1016/S0301-6226(99)00015-9

Ducat DC, Silver PA (2012) Improving carbon fixation pathways. Current Opinion in Chemical Biology 16: 337-344. https://doi.org/10.1016/j.cbpa.2012.05.002

Dussadee N, Ramaraj R, Cheunbarn T (2017) Biotechnological application of sustainable biogas production through dry anaerobic digestion of Napier grass. Biotech 7:47

Environmental Protection Administration (Taiwan EPA) (2018) Water Pollution Control Act. Executive Yuen, Taiwan, ROC

Food and Agriculture Organization (FAO) (2020) Major cuts of greenhouse gas emissions from livestock within reach: GHG emissions by livestock. United Nations http://www.fao.org/news/story/en/item/197623/icode/

Garfi M, Marti-Herrero J, Garwood A, Ferrer I (2016) Household anaerobic digesters for biogas production in Latin America: a review. Renew Sust Energ Rev 60:599-614

Godbout S, Pelletier FP, Hamelin L, Lemay SP, Belzile M, Laverdière MR, Côté C, Giroux M, Pouliot F, Quessy S (2008) Problématiques environnementales émergentes en production animale. IRDA-CRAAQ, Quebec, pp 45-60

Goswami R, Chattopadhyay P, Shome A, Banerjee SN, Chakraborty AK, Mathew AK, Chaudhury A (2016) An overview of physico-chemical mechanisms of biogas production by microbial communities: a step towards sustainable waste management. 3 Biotech 6:72 https://doi.org/10.1007/s13205-016-0395-9 
Grossi G, Goglio P, Vitali A, Williams AG (2018) Livestock and climate change: impact of livestock on climate and mitigation strategies. Animal Frontiers 9: 69-76. https:doi.org/10.1093/af/vfy034

Guinée JB, Gorrée M, Heijungs R, Huppes G, Kleijn R, de Koning A, van Oers L, Wegener Sleeswijk A, Suh S, Udo de Haes HA, de Bruijn $H$, van Duin R, Huijbregts MAJ (2002) Handbook on life cycle assessment, operational guide to the ISO standards, Part III: Scientific background. Kluwer Academic Publishers, Dordrecht, pp 401-644

Hellweg S, Mila i Canals L (2014). Emerging approaches, challenges and opportunities in life cycle assessment. Science 344: 1109-1113. http://doi.org/10.1126/science.1248361

Huijbregts MAJ, Steinmann ZJN, Elshout PMF, Stam G, Verones F, Vieira MDM, Hollander A, Zijp M, van Zelm R (2017) ReCiPe2016: a harmonized life cycle impact assessment method at midpoint and endpoint level. The International Journal of Life Cycle Assessment 22: 138-147.

https://doi.org/10.1007/s11367-016-1246-y

International Organization for Standardization (ISO) (2006) Environmental management-life cycle assessment-principles and framework, ISO 14040-14044:2006(en). Geneva, Switzerland

International Organization for Standardization (ISO) (2018) Greenhouse gases - carbon footprint of products - requirements and guidelines for quantification, ISO 14067:2018(en). Geneva, Switzerland

IPCC (2013) The Physical science basis. Contribution of working group I to the fifth assessment report of the intergovernmental panel on climate change. In: Stocker TF, Qin D, Plattner G-K, Tignor M, Allen SK, Boschung J, Nauels A, Xia Y, Bex V, Midgley PM (eds) Climate Change 2013. Cambridge University Press, Cambridge and New York, pp 1535

Ishikawa S, Hoshiba S, Hinata T, Hishinuma T, Morita S (2006) Evaluation of a biogas plant from life cycle assessment (LCA). International Congress Series 1293: 230-233 https://doi.org/10.1016/j.ics.2006.02.008

Mabee WE, Saddler JN (2010) Bioethanol from lignocellulosics: status and perspectives in Canada. Bioresource Technology 101: 4806-4813 https://doi.org/10.1016/j.biortech.2009.10.098

Nasir IM, Ghazi TIM, Omar R (2012) Anaerobic digestion technology in livestock manure treatment for biogas production: A review. Engineering In Life Sciences 12: 258-269 https://doi.org/10.1002/elsc.201100150

Petersson A, Wellinger A (2009) Biogas upgrading technologies-developments and innovations. IEA Bioenergy Technology Collaboration Programme (TCP), pp 19

Putmai N, Jarunglumlert T, Prommuak C, Pavasant P, Flood AE (2020) Modelling of swine farm management for enhancement of biogas production and energy efficiency. IOP Conference Series: Materials Science and Engineering 736: 022051 https://doi.org/10.1088/1757-899x/736/2/022051 
Ro KS, Novak JM, Johnson MG, Szogi AA, Libra JA, Spokas KA, Bae S (2016) Leachate water quality of soils amended with different swine manure-based amendments. Chemosphere 142: 92-99 https://doi.org/10.1016/j.chemosphere.2015.05.023

Roubík H, Mazancová J (2020) Suitability of small-scale biogas systems based on livestock manure for the rural areas of Sumatra. Environmental Development 33: 100505 https://doi.org/10.1016/j.envdev.2020.100505

SimaPro v.8.4 software (2017) PRè Sustainability Consultant: Amersfoort, the Netherlands

Schnürer A (2016) Chapter 5 in Advances in Biochemical Engineering/Biotechnology Biogas Production: Microbiology and Technology, Springer International Publishing Switzerland https://doi.org/10.1007/10_2016_5

Tsai W-T, Lin C-I (2009) Overview analysis of bioenergy from livestock manure management in Taiwan. Renewable and Sustainable Energy Reviews 13: 2682-2688 https://doi.org/10.1016/j.rser.2009.06.018

Usack JG, Gerber Van Doren L, Posmanik R, Labatut RA, Tester JW, Angenent LT (2018) An evaluation of anaerobic co-digestion implementation on New York State dairy farms using an environmental and economic life-cycle framework. Applied Energy 211: 28-40

https://doi.org/10.1016/j.apenergy.2017.11.032

Weidema B P, Bauer C, Hischier R, Mutel C, Nemecek T, Reinhard J, Vadenbo CO, Wernet G (2013) Overview and methodology. Data quality guideline for the ecoinvent database version 3 . Ecoinvent Report 1(v3). St. Gallen: The ecoinvent Centre

\section{Figures}

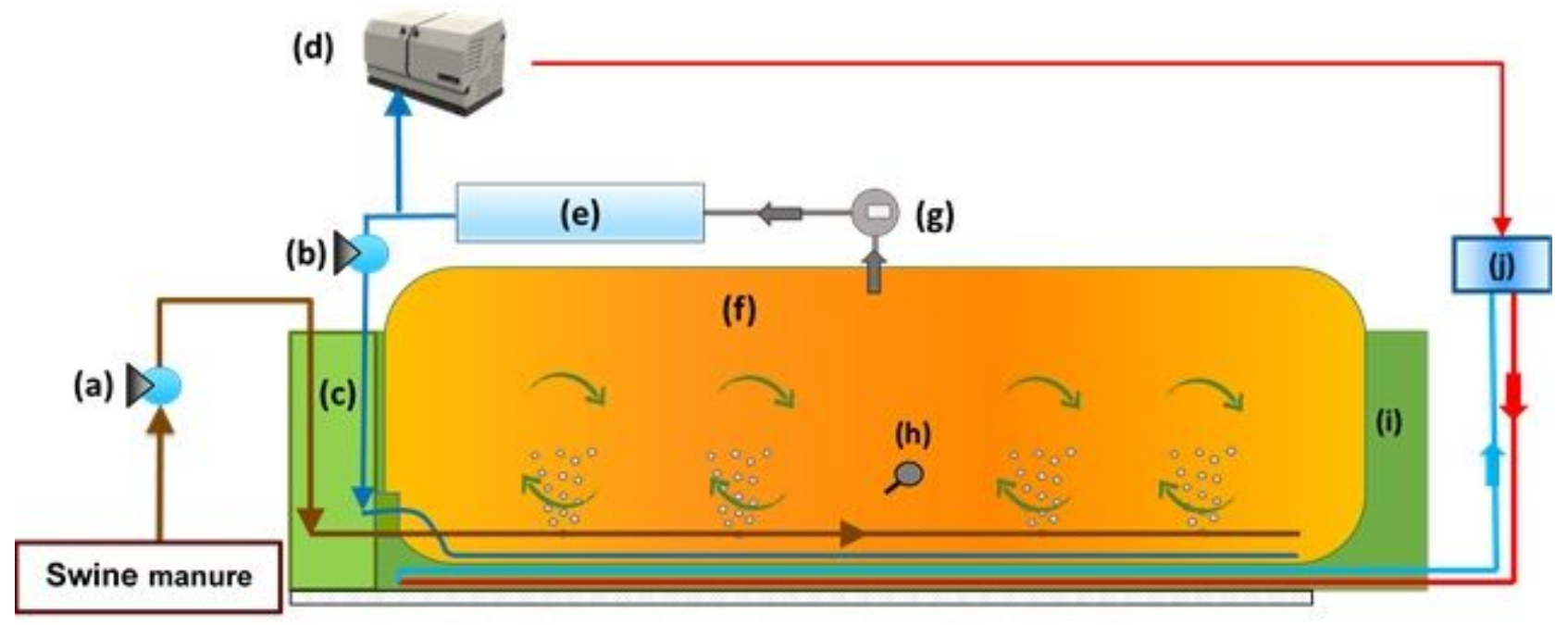

(a) Feeding pump (b) Biogas pump (c) Feeding tank (d) Biogas engine (e) Desulfurizer (f) PCV Biogas bag (g) Biogas flow meter (h) Thermal meter (i) container (j) Heat exchanger 
Figure 1

Schematic diagram of container anaerobic fermentor.

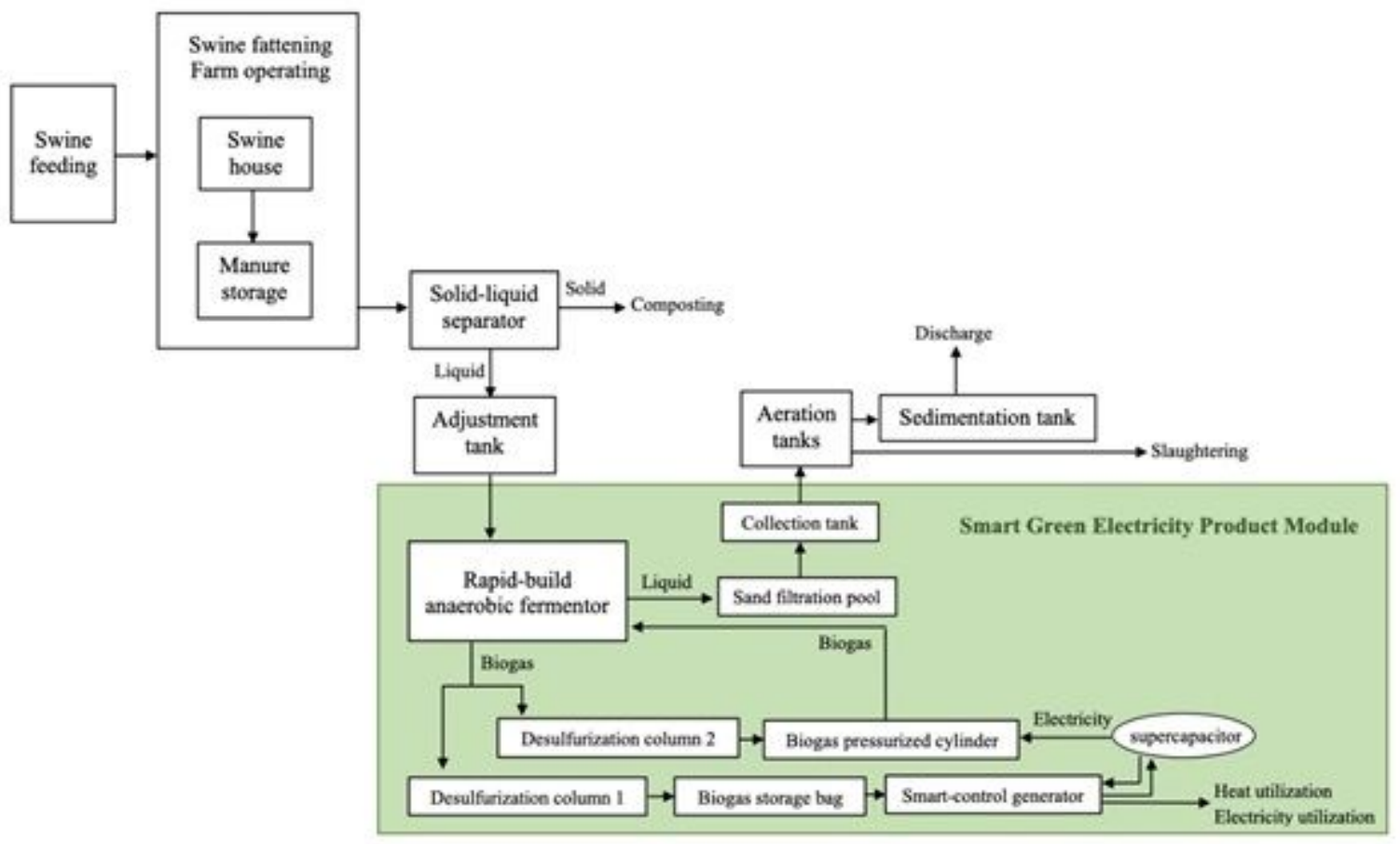

\section{Figure 2}

The Smart Green Electricity Production Module and operation principle.

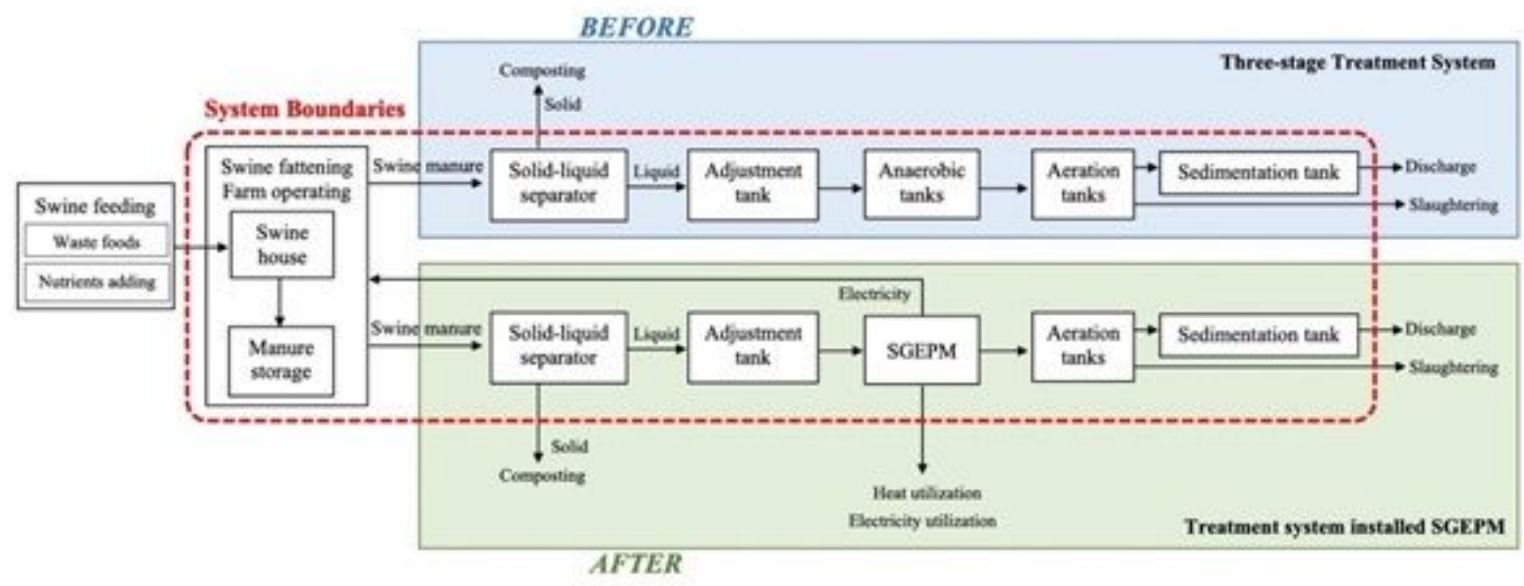

\section{Figure 3}

Scope and boundary of life cycle assessment (LCA) for swine farm operating integrated with the threestage wastewater treatment system or transformation with the SGEPM. 


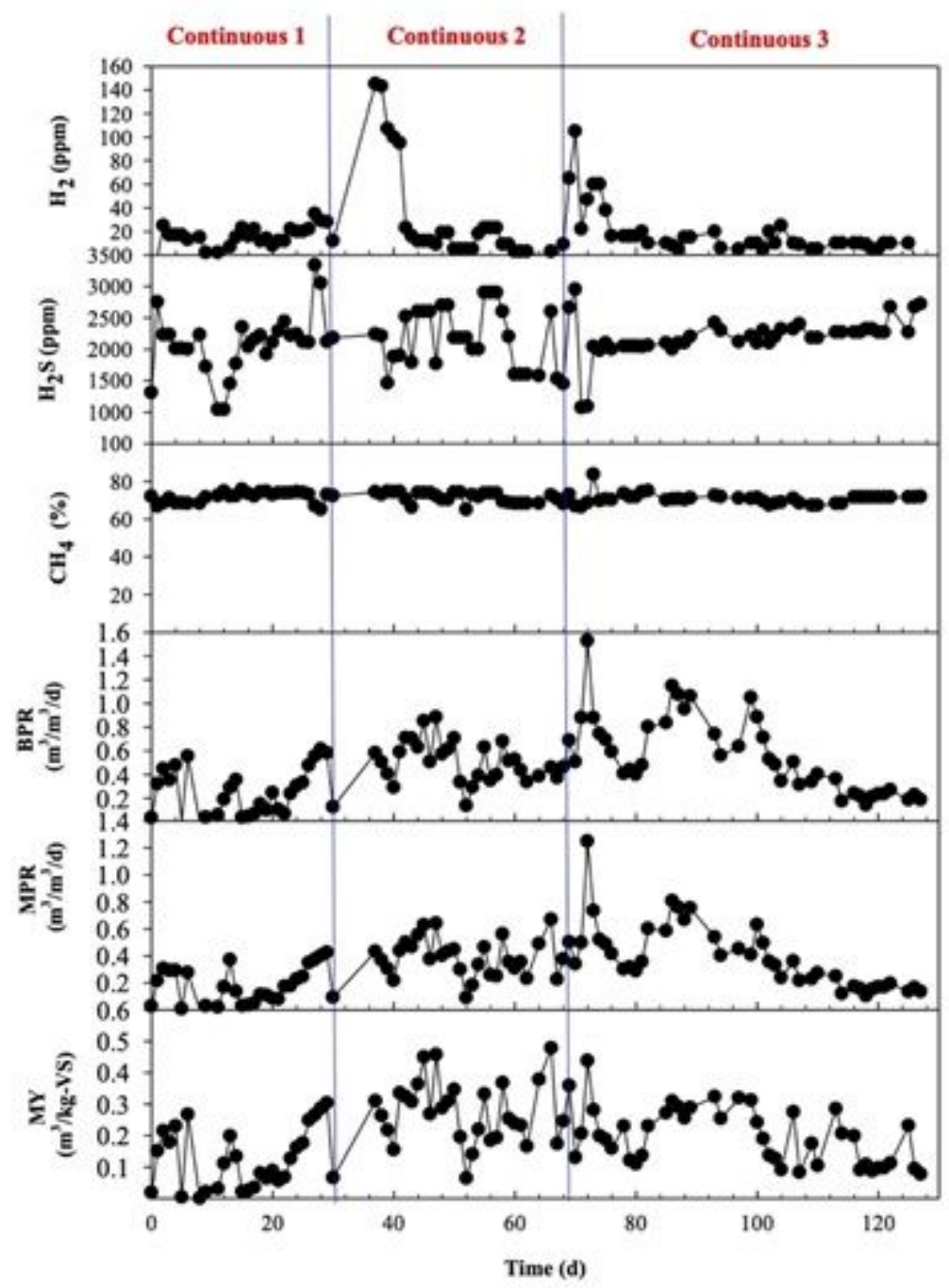

Figure 4

Biogas production performance at various continuous cultivation periods in the container anaerobic fermentor 


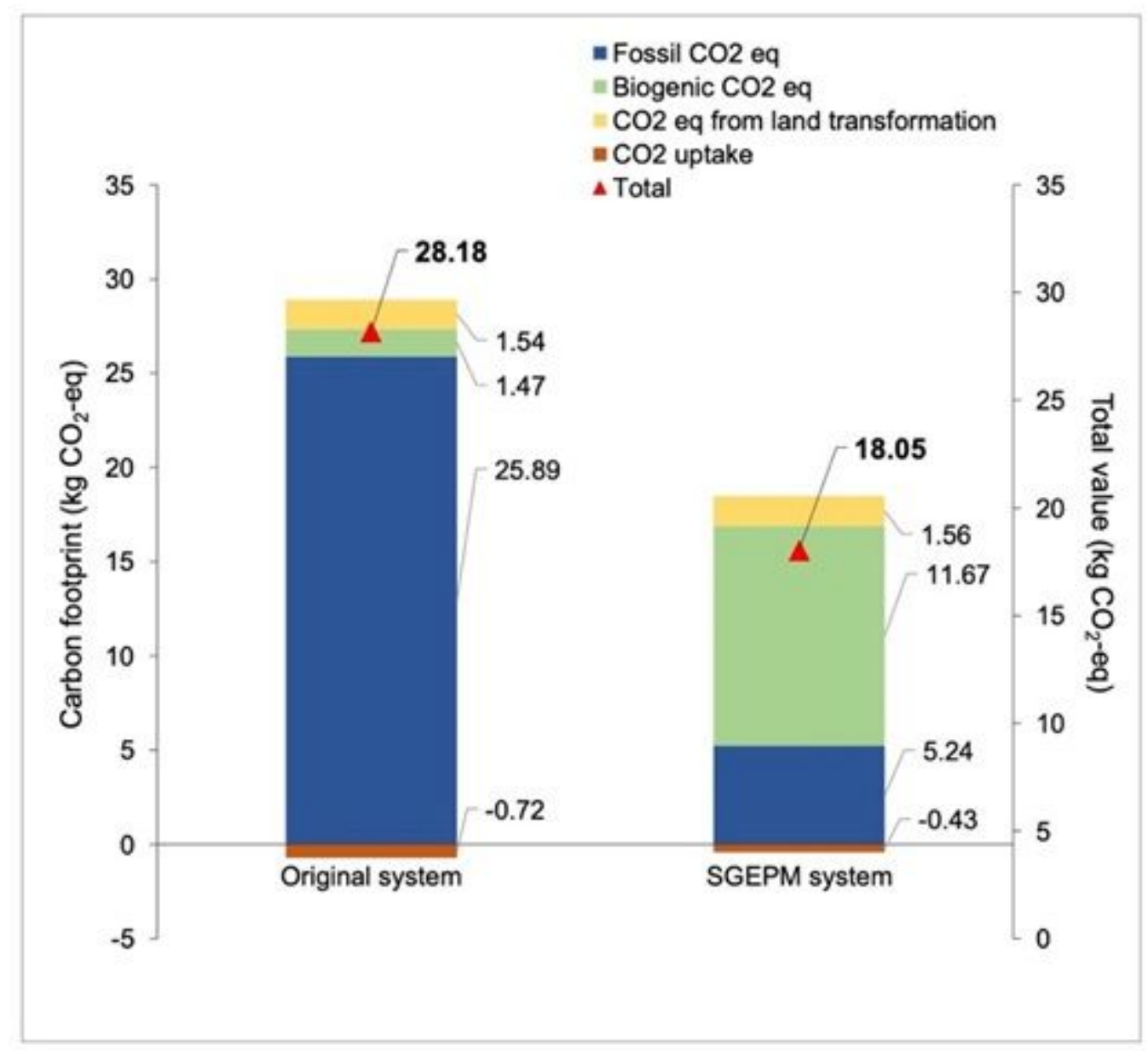

Figure 5

Contributions of carbon footprint inventory by the original three-stage wastewater treatment system and after installed the SGEPM. 


\section{= SGEPM system = Original system}

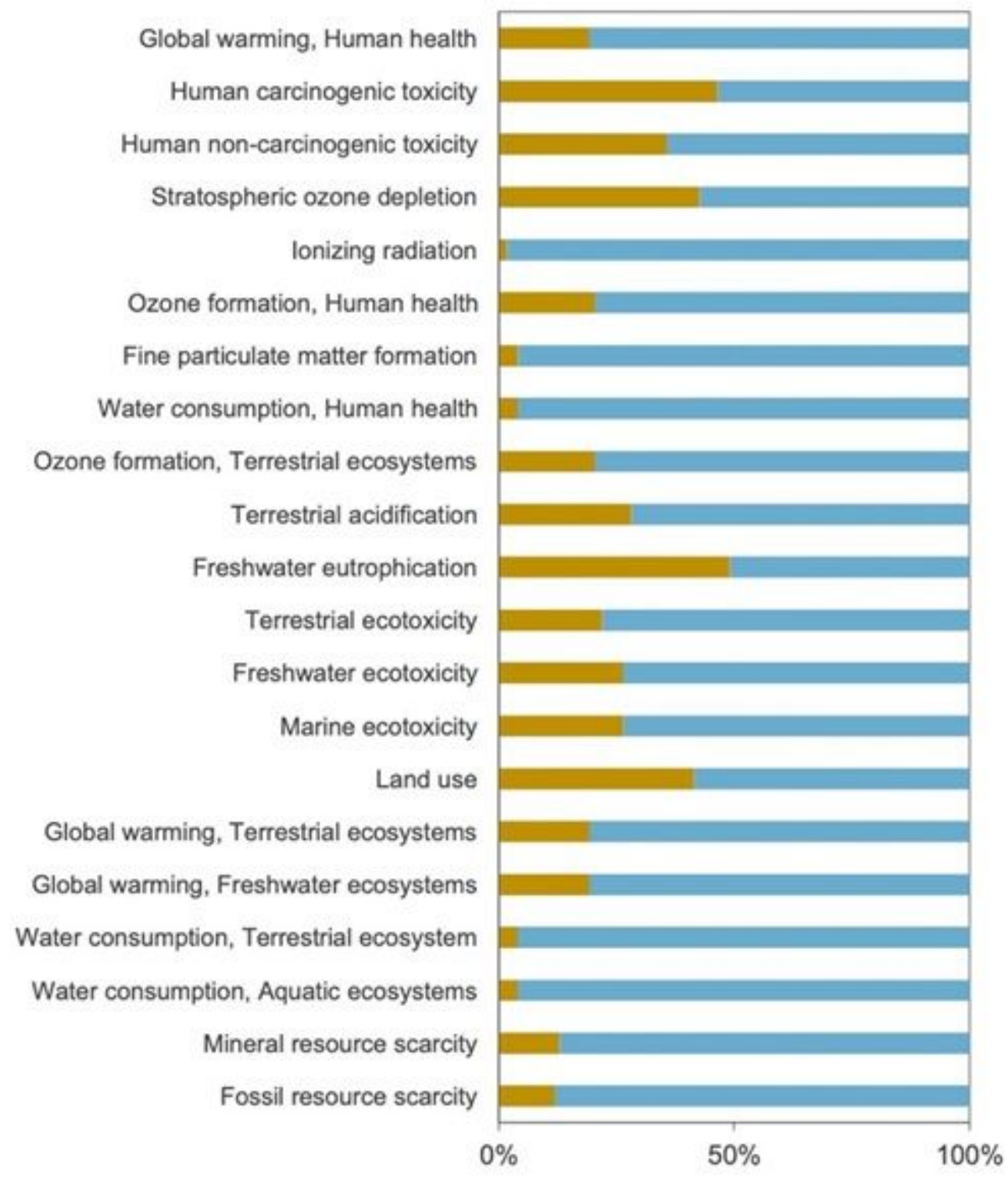

\section{Figure 6}

The relative contribution of the original three-stage wastewater treatment system and after installed the SGEPM, in terms of impact categories in the midpoint. 


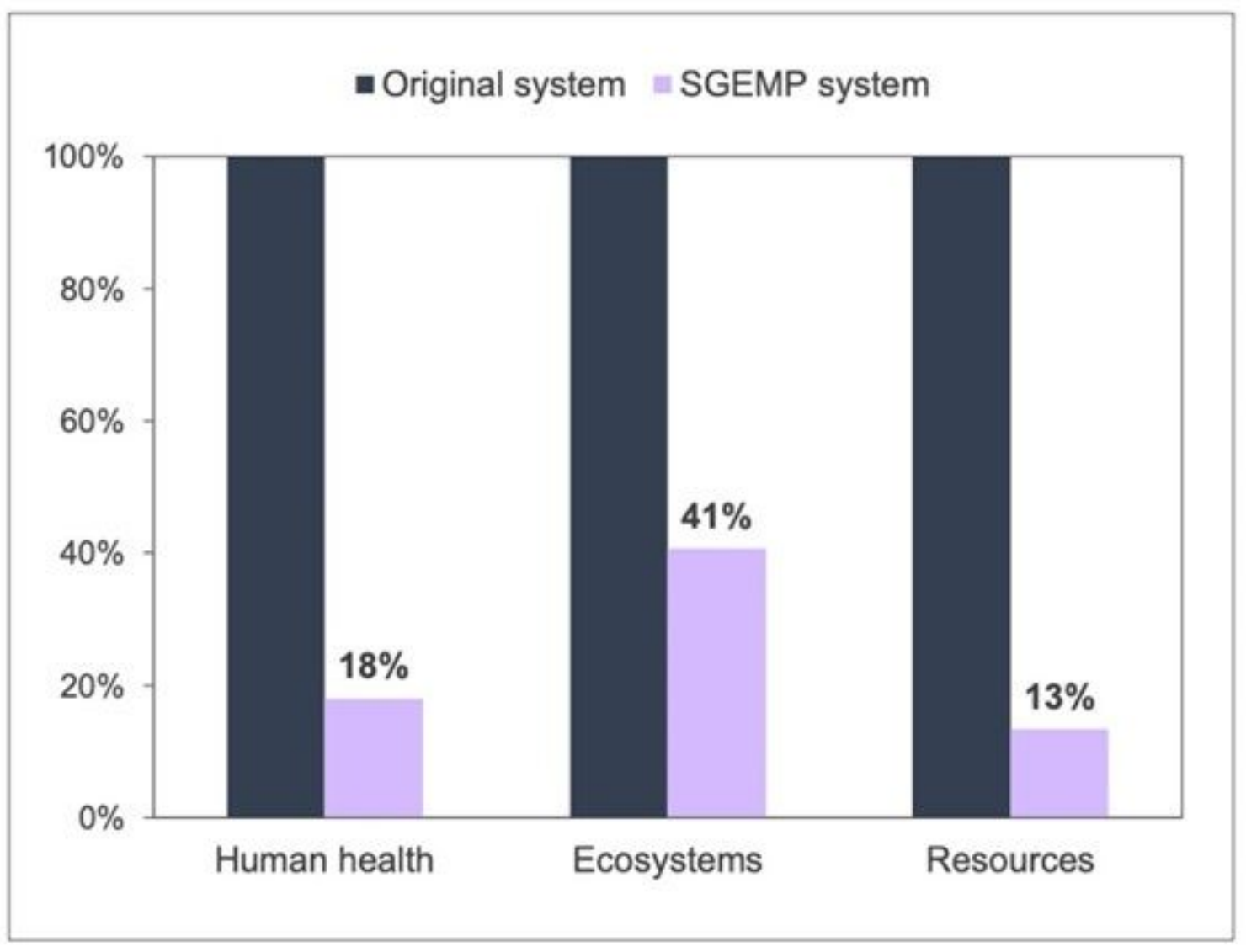

Figure 7

Comparison of damage impacts at the endpoint level for the original three-stage wastewater treatment system and after installed the SGEPM.

\section{Supplementary Files}

This is a list of supplementary files associated with this preprint. Click to download.

- Graphicalabstractrevised.docx 